\title{
Analysis of positioning deviation between Beidou and GPS based on National Reference Stations in China
}

\author{
Ming Chen ${ }^{1}$, Qinglan Zhang ${ }^{1,2}$ \\ ${ }^{1}$ National Geomatics Center of China, Beijing, China - (cm,qinglanzhang)@ngcc.cn \\ ${ }^{2}$ GNSS Center, Wuhan University, Wuhan, China
}

KEY WORDS: Beidou, GPS, Deviation characteristics, Reference stations, Consistency.

\begin{abstract}
:
In order to probe into the characteristics of positioning deviation between Beidou Navigation Satellite System (Beidou) and global positioning system (GPS), and investigate possible contribution of Beidou data to refinement of global coordinate system, refined calculation is made on observation data of 240 national reference stations that are distributed uniformly across China on the whole in this study. These stations support satellite signals of four global navigation satellite systems, including Beidou, GPS, GLONASS and Galileo, and a 5-year time span from 2016 to 2020 is adopted. In this study, PPP is calculated based on GPS data and Beidou single system data in no-difference resolution network mode, and accurate coordinates of national reference stations in two processing modes are obtained. Analysis of difference between the calculations based on Beidou data and on GPS data shows that the consistency between Beidou and GPS positioning results reaches about $5 \mathrm{~mm}$ in the east and in the north, and about $1.3 \mathrm{~cm}$ in the height direction.
\end{abstract}

\section{INTRODUCTION}

In recent years, global navigation satellite system (GNSS) has developed rapidly. There are four GNSS including US GPS, the Chinese Beidou, the Russian GLONASS and the European Galileo system. Among them, Beidou satellite navigation system has adopted a "three-step" approach to construction, from active to passive and from regional to global. On December 28, 2012, the construction of Beidou-2 system was completed. On July 31, 2020, Beidou-3 system will be officially opened, marking the successful completion of the three-step development strategy of Beidou and a new era of global service.

Constructing a Beidou coordinate frame is prerequisite for precision orbit determination and positioning as well as efficient application of Beidou. Its main purposes are to define coordinate system of the Beidou Satellite Navigation System, research the theories and methods of implementing and maintaining coordinate system in peacetime and wartime, provide solutions to refinement of geocentric coordinates of ground monitoring station of China's global satellite navigation system, determine the conversion relation between China's independent coordinate system and geodetic coordinate systems such as international terrestrial reference frame (ITRF) (Altamimi Z et al.,2011,2016), WGS84, PZ-90, GTRF and so much more and estimate conversion accuracy, to address the needs of navigation, positioning and orbit determination of the Beidou Navigation Satellite System.

Regarding construction and maintenance of Beidou coordinate frame, Chen et al.,(2008) proposed China Geodetic Coordinate System 2000(CGCS2000) and corresponding frame construction method; Liu et al.(2009) considered about updating national geocentric dynamic coordinate frame by constructing national continuously operating reference station (CORS); Wei et al.(2013) proposed to adopt "Beidou coordinate system" for Beidou Navigation Satellite System and gave the definition; Zou(2011) simulated the construction and maintenance of Beidou coordinate frame with data from IGS tracking stations and from some Beidou tracking stations at that time, providing a reference for construction of real Beidou coordinate frame; Wei et al.(2014) preliminarily realized Beidou frame by virtue of GPS data and short-term dual-mode station data, and figured out the speed of $0.3 \mathrm{~mm} / \mathrm{yr}$ in horizontal direction, and $0.9 \mathrm{~mm} / \mathrm{yr}$ in perpendicular direction ; Zeng et al.(2015) discussed construction, connection and data processing of Beidou reference station, and offered some proposals. Shi et al (2017) solely utilized Beidou data to obtain station residual plane repeatability and height repeatability prior to $0.8 \mathrm{~cm}$ and $1.7 \mathrm{~cm}$ respectively. The construction and maintenance of Beidou coordinate frame require long-time data accumulation. Beidou data of more than five years can be obtained at present, which lays a foundation for calculating out a long-time reliable and accurate Beidou coordinate frame. It is worth mentioning that since the long-time Beidou data of China's national reference stations is mainly obtained from Beidou-2 and rarely from Beidou-3, the analysis of positioning error of Beidou and GPS in this study is mainly based on Beidou-2 data.

In the implementation of the Beidou coordinate framework, the observation data of the national reference station supporting the Beidou and GPS dual systems are used, and the GPS and Beidou observation data are used for data processing respectively. The GPS data of IGS station and national reference station are used for precise network solution to obtain the geocentric coordinates of the reference station under ITRF framework, which can be used as the initial implementation of Beidou coordinate framework based on GPS technology. The data processing based on Beidou data can take the coordinates and speed under ITRF framework as constraints, and get the initial implementation of Beidou coordinate framework based on Beidou technology. In this way, the obtained Beidou coordinate framework can meet the high precision of ITRF framework at the same time, and also maintain internal consistency. 
One important task of constructing Beidou coordinate frame is to analyze Beidou positioning accuracy and the difference from GPS positioning error. Shi et al.(2012) systematically analyzed Beidou positioning accuracy and figured out centimeter-level static PPP accuracy, centimeter-level relative positioning accuracy and RTK positioning accuracy as good as $5-10 \mathrm{~cm}$; Gao et al.(2012) researched unification of Beidou and GPS spatio-temporal systems and realized Beidou/GPS data integration and joint positioning; Yang et al.(2014) evaluated the performance of Beidou Navigation Satellite System in basic navigation and positioning, and concluded that Beidou is comparable to GPS in respect of pseudo distance and carrier phase measurement accuracy but is still far inferior to GPS concerning single-frequency pseudo distance differential positioning due to multi-path and big error of Beidou GEO satellite pseudo distance; Wang et al.(2014) conducted contrastive analysis of precise point positioning accuracy between Beidou and GPS, and figured out Beidou PPP accuracy of $1-2 \mathrm{~cm}$ in horizontal direction and $3-4 \mathrm{~cm}$ in perpendicular direction. Liu et al.(2020) compared the CGCS2000 coordinates calculated from Beidou data of city-class reference stations with the coordinates calculated from GPS data, and obtained RMS values in plane and height direction of 3.1 and $4.2 \mathrm{~mm}$ respectively.

In order to probe into the characteristics of positioning deviation between Beidou and GPS, and investigate possible contribution of Beidou data to refinement of global coordinate system, in this paper, the observation data of 240 national reference stations in China are calculated accurately, and the differences between the two positioning results are analyzed.

\section{MATERIALS AND METHODS}

\subsection{Data Resources}

In 2016, China's national department of surveying, mapping and geographic information completed construction of 240 national satellite navigation and positioning reference stations uniformly distributed across the country, set up a national data center, built a data exchange and sharing platform for reference stations across the country, established 31 data transmission backbone networks between the national data center and provincial data centers, and developed a national satellite navigation and positioning reference service system, which provides a unified authoritative national coordinate frame for domestic satellite navigation and positioning service, and can realize rapid realtime high precision navigation and positioning service at meter level and decimeter level as well as national-local and interindustry data exchange and resource sharing. The distribution of Chinese national GNSS reference stations is as below:

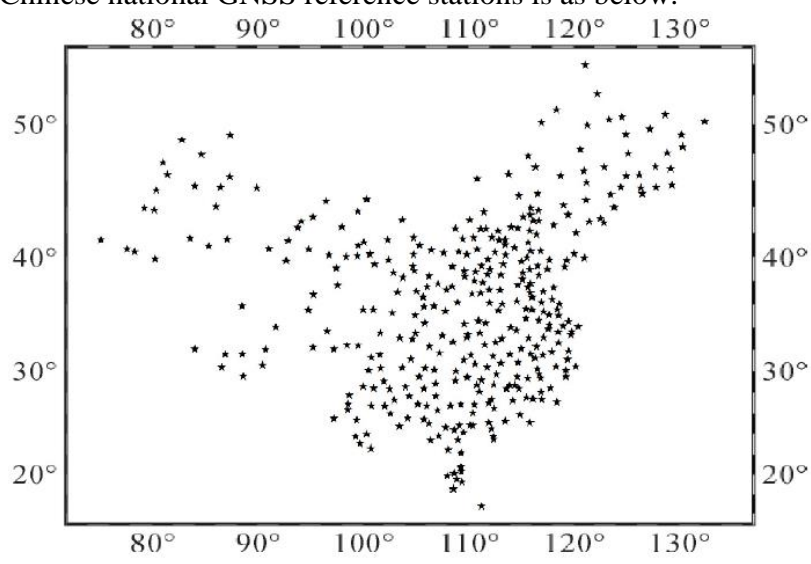

Figure 1. The distribution of Chinese national GNSS reference stations (This figure is a schematic diagram of the topic and does not involve national territory information)

The national GNSS reference stations run via unattended fullautomatic operation of high reliability under guard, incessantly trace and observe satellite signal data around the clock, realize real-time data transmission to data centers via dedicated data transmission networks, and have the functions of data collection from multiple satellite systems, integrity monitoring, reliability analysis and satellite orbit determination. National GNSS reference stations are capable of incessantly collecting data from multiple satellite navigation systems, including Beidou, GPS, GLONASS and Galileo, and providing data services of various satellite ephemeris and clock biases at different grades, which are a key infrastructure supporting the multifunctional navigation application service system. The national GNSS reference stations are uniformly distributed across the country on the whole. Specifically, the distribution in the east is relatively dense at the consideration of current development situation in the east, and in the west is relatively sparse (Chen Ming et al., 2016). Basic information of Chinese national GNSS reference stations is as below:

\begin{tabular}{|c|c|c|}
\hline Content & Indicator & Remark \\
\hline Coverage & $\begin{array}{c}\text { Nationwi } \\
\text { de }\end{array}$ & $\begin{array}{c}\text { Can be extended to greater } \\
\text { coasting area }\end{array}$ \\
\hline Number of stations & 410 & \\
\hline Shortest edge & $41 \mathrm{~km}$ & Xuzhou to Suzhou \\
\hline Longest edge & $1160 \mathrm{~km}$ & $\begin{array}{c}\text { Mount Qomolangma to } \\
\text { Luopu }\end{array}$ \\
\hline $\begin{array}{l}\text { Mean station } \\
\text { distance }\end{array}$ & $200 \mathrm{~km}$ & \\
\hline $\begin{array}{c}\text { Data transmission } \\
\text { network }\end{array}$ & $\begin{array}{c}\text { 10Mbps } \\
\text { MSTP }\end{array}$ & $\begin{array}{l}\text { Bandwidth of backbone } \\
\text { network is } 10 \mathrm{Mbps}\end{array}$ \\
\hline $\begin{array}{l}\text { Receiver } \\
\text { equipment }\end{array}$ & $\begin{array}{l}\text { Trimble } \\
\text { NetR9 }\end{array}$ & $\begin{array}{c}\text { Support Beidou, GPS, } \\
\text { GLONASS, Galileo systems }\end{array}$ \\
\hline
\end{tabular}

Table 1. Basic Information of Chinese National GNSS Reference Stations.

The 240 national GNSS reference stations all are equipped with Trimble NetR9 GNSS receiver and TRM59900.00 GNSS antenna, process observation data of a 5-year period from Jan. 1, 2016 to Dec. 31, 2020, and conduct single-day solution of GPS and Beidou separately. For GPS data processing, 51 IGS core stations are added for joint solution.

\subsection{Calculation process}

For purpose of this study, the Position and Navigation Data Analyst (PANDA) developed by Wuhan University is employed for data processing. The data calculation process is as Figure 2.

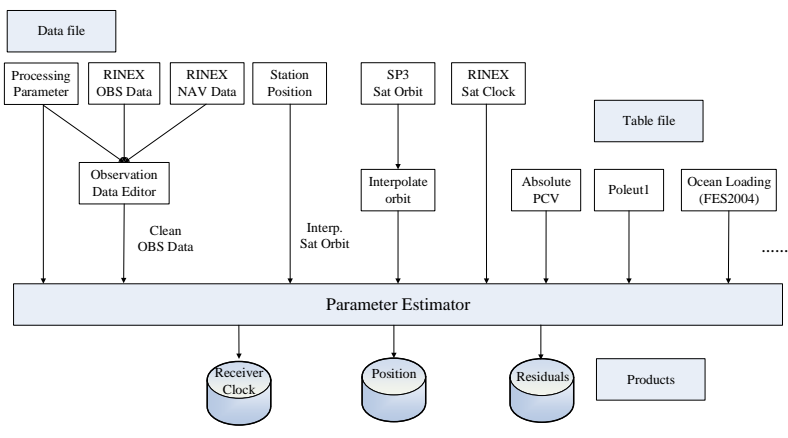

Figure 2. PPP calculation process

In this paper, non difference PPP positioning method is used for data calculation. Firstly, the observation data file, precise 
ephemeris and clock error file, table file and other data should be prepared, then the data format conversion and data preprocessing should be carried out to get clean data, and then the parameter estimation should be carried out according to the error correction model and calculation strategy to get the calculated unknown parameters. The unknown parameters include station three-dimensional coordinates, receiver clock error, tropospheric delay and ionospheric free combination ambiguity. The least square parameter estimation method is used to estimate the unknown parameters. For the eliminated parameters, the information is not eliminated and still remains in the normal equation, which can be solved by parameter recovery. The data processing strategies are as Table 2 .

\begin{tabular}{|c|c|}
\hline Item & Description \\
\hline Processing & PPP \\
\hline Observations & $\begin{array}{c}\text { Ionosphere-free combination of } \\
\text { GPS/Beidou }\end{array}$ \\
\hline Sampling & $30 \mathrm{~s}$ \\
\hline Processing sessions & 24hours \\
\hline $\begin{array}{l}\text { Elevations cut-off } \\
\text { angle }\end{array}$ & $7^{\circ}$, weighted below $30^{\circ}$ \\
\hline $\begin{array}{l}\text { Satellite orbits and } \\
\text { clocks }\end{array}$ & $\begin{array}{l}\text { Fixed with satellite products from IGS } \\
\text { center }\end{array}$ \\
\hline ERPs & Fixed with IERs 08 C04 products \\
\hline Ambiguity & $\begin{array}{l}\text { Resolved to integer values (Ge et } \\
\text { al.2005) }\end{array}$ \\
\hline $\begin{array}{l}\text { Tropospheric } \\
\text { refraction }\end{array}$ & $\begin{array}{l}\text { A prior model with remaining } \\
\text { estimated as piecewise constant }\end{array}$ \\
\hline $\begin{array}{l}\text { Ionospheric } \\
\text { refraction }\end{array}$ & $\begin{array}{l}\text { First order is eliminated by } \\
\text { ionosphere-free combination, and } \\
\text { higher orders are ignored }\end{array}$ \\
\hline Antenna phase center & Corrected with igs08.atx/igs14.atx \\
\hline Ocean tide & FES2004 model (Lyard et al.2006) \\
\hline Solid Earth tide & $\begin{array}{c}\text { IERS conversion 2010(Petit and } \\
\text { Luzum,2010) }\end{array}$ \\
\hline Pole tide & $\begin{array}{c}\text { IERS conversion 2010(Petit and } \\
\text { Luzum,2010) }\end{array}$ \\
\hline Atmosphere loading & None \\
\hline
\end{tabular}

Table 2. PPP calculation strategies

For the table above, different precision satellite orbit and atx products from IGS data centers were adopted depending on the actual situation in different periods. Concerning GPS data processing, igs08_wum.atx was employed from Jan. 1, 2016 until Jan. 28, 2017, and igs14.atx from Jan. 29, 2017 until Dec. 31, 2020, and igswwwwd.sp3 file (precision satellite orbit) had been being employed (wwww refers to GPS week, and d to day of the week). Concerning Beidou data processing, igs08_wum.atx was employed from Jan. 1, 2016 until Jan. 28, 2017, igs14_wum.atx from Jan. 29, 2017 until Dec. 31, 2018, and igs14.atx during the 2019-2020 period. The calculation of BDS data in this study is based on B1 and B2 data. To maintain data source consistency of satellite orbit determination and reference station positioning calculation, it is suggested to employ precision satellite orbit products developed on the basis of $\mathrm{B} 1$ and $\mathrm{B} 2$ for Beidou calculation as far as possible. In view of this, wumwwwwd.sp3 released by Wuhan University was employed from 2016 until 2018, and codwwwwd.sp3 developed on the basis of B1 and B2 data was chosen for calculation of 2019-2020 Beidou data despite that the basis on which the orbit products released by most IGS data centers including Wuhan University changed into B1 and B3 data since 2019.

\section{RESULTS AND DISCUSSION}

\subsection{Station Coordinates Residual}

Since precise point positioning solution in this study is conducted on the basis of observation data of a continuous 5year period from 2016 to 2020 from Chinese national GNSS reference stations and the time span is large, linear variation is unavoidable for the calculated station coordinates. Table 3 shows RMS values of time series of coordinates of Chinese national GNSS reference stations after elimination of linear velocity. As shown, the RMS values based on GPS data are $0.27 \mathrm{~cm}$ and $0.28 \mathrm{~cm}$ respectively in directions $\mathrm{E}$ and $\mathrm{N}$, and $0.77 \mathrm{~cm}$ in direction $\mathrm{U}$. The RMS values of coordinates residual based on BDS data all are obviously larger than that based on GPS data approximately by quadruple in direction $\mathrm{E}$ and triple in directions $\mathrm{N}$ and $\mathrm{U}$. Reason analysis shows that repeatability accuracy of station coordinates is inversely proportional to time span due to imperfection of Beidou error correction model.

\begin{tabular}{|c|c|c|c|}
\hline \multirow{2}{*}{ Stations } & \multicolumn{3}{|c|}{ RMS(cm) } \\
\cline { 2 - 4 } & $\mathrm{E}$ & $\mathrm{N}$ & $\mathrm{U}$ \\
\hline GPS & 0.27 & 0.28 & 0.77 \\
Beidou & 1.14 & 0.79 & 2.27 \\
\hline
\end{tabular}

Table 3.RMS of Time Series of Coordinates of Chinese National GNSS Reference Stations

Since two different precision satellite orbit products were employed for BSD data calculation before and after Jan. 1, 2019, statistics of coordinate repeatability for the two periods were developed respectively. The results show that the RMS values in the three directions are $1.38 \mathrm{~cm}, 0.91 \mathrm{~cm}$ and $2.61 \mathrm{~cm}$ in the first period respectively, and $0.61 \mathrm{~cm}, 0.57 \mathrm{~cm}$ and $1.54 \mathrm{~cm}$ in the second period respectively. In the second period, the Beidoubased RMS values are approximately twice of GPS-based RMS values. In the first period, the Beidou-based RMS values are about triple of GPS-based RMS values in directions $\mathrm{N}$ and $\mathrm{U}$ and quadruple in direction E. This is mainly because different precision satellite orbit products were employed.

To visually present the characteristics of time series residual of coordinates based on GPS data and on BSD data, national GNSS reference stations AHBZ (first stations of all national GNSS reference stations in alphabetical order, located in Anhui Province, China) were selected at random for mapping. Figure 3 shows time series of coordinates calculated from GPS data and from BSD data respectively. It is observed that the coordinates calculated from GPS data are obviously better than that from BSD data in respect of repeatability, and show significant linear variation in directions $\mathrm{E}$ and $\mathrm{N}$ and relatively seasonal variation in direction $\mathrm{U}$ in addition to subsidence. Coordinates calculated from BSD data and that from GPS data take on a consistent trend at a close linear velocity with a slightly large difference in the height direction. It is also observed that the coordinates calculated from BDS data after 2019 is superior to that before 2019 in respect of repeatability due to difference in precision satellite orbit. 

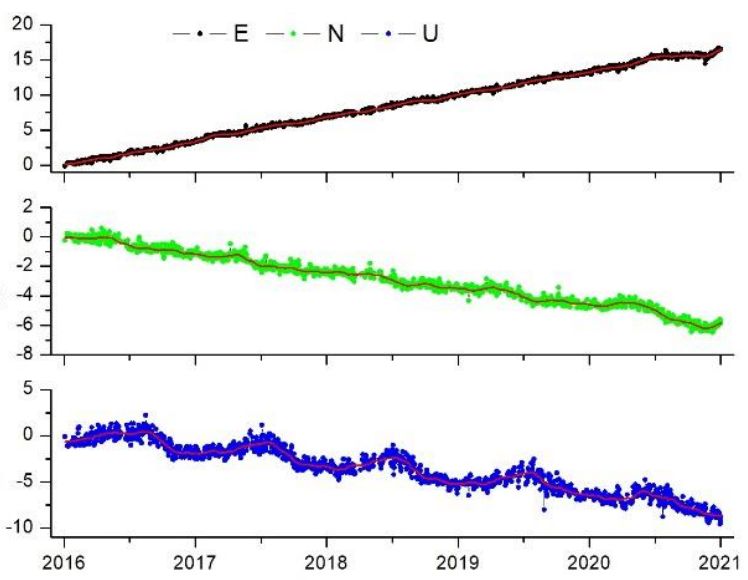

a) Coordinates calculated from GPS data $(\mathrm{cm})$
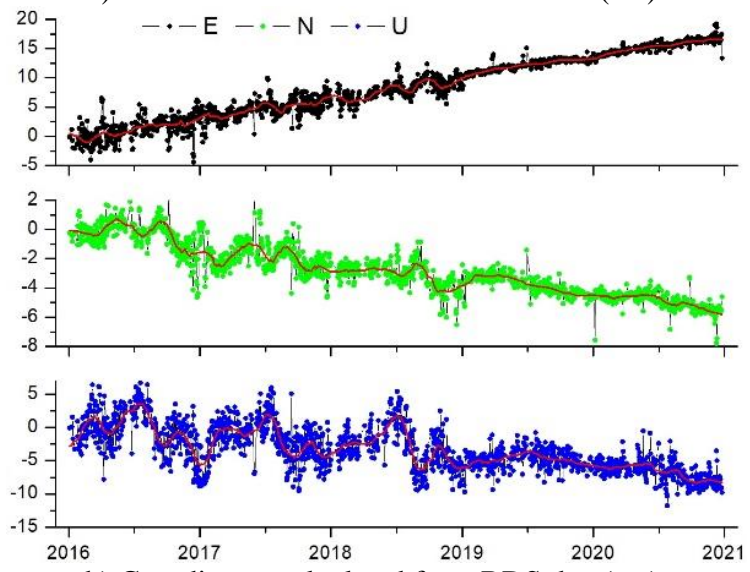

b) Coordinates calculated from BDS data $(\mathrm{cm})$

Figure 3. Comparison of Linear Velocity of Time Series Residual of Station Coordinates

To analyze seasonal variation of station coordinates, the linear velocity of time series of coordinates of stations AHBZ is eliminated, as shown in Figure 4. Figures 4 a) and 2 b) show time series residual of station coordinates calculated from GPS data and from BDS data after elimination of linear velocity respectively. It is observed that the GPS results show better repeatability, with residual repeatability better than $1 \mathrm{~cm}$ in directions $\mathrm{E}$ and $\mathrm{N}$ and better than $3 \mathrm{~cm}$ in direction $\mathrm{U}$, and taking on obvious seasonal variation on yearly basis (especially obvious in height direction). The overall trend of coordinates calculated from BDS data is consistent with that from GPS data. Concerning seasonal variation, the coordinates calculated from BDS data is slightly inferior to that from GPS data in respect of repeatability accuracy and seasonal variation although the trend is presented roughly.
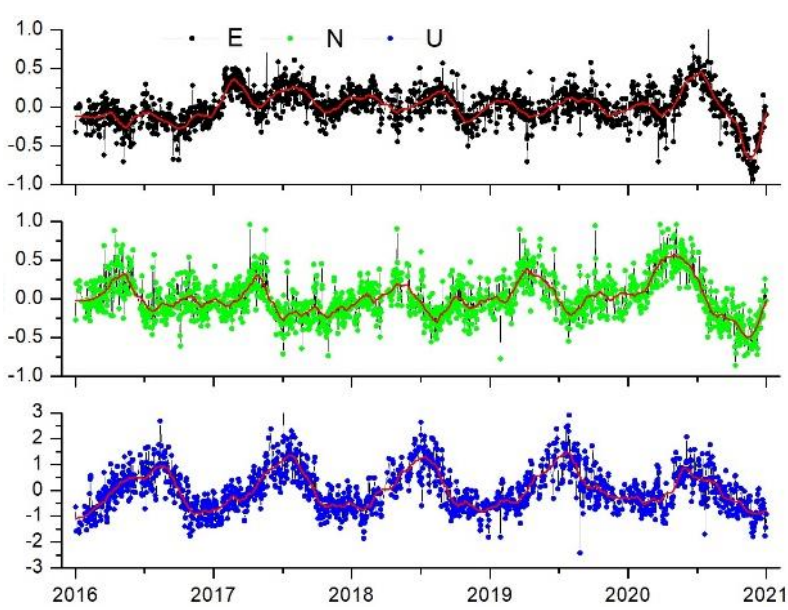

a) GPS coordinates time series residual
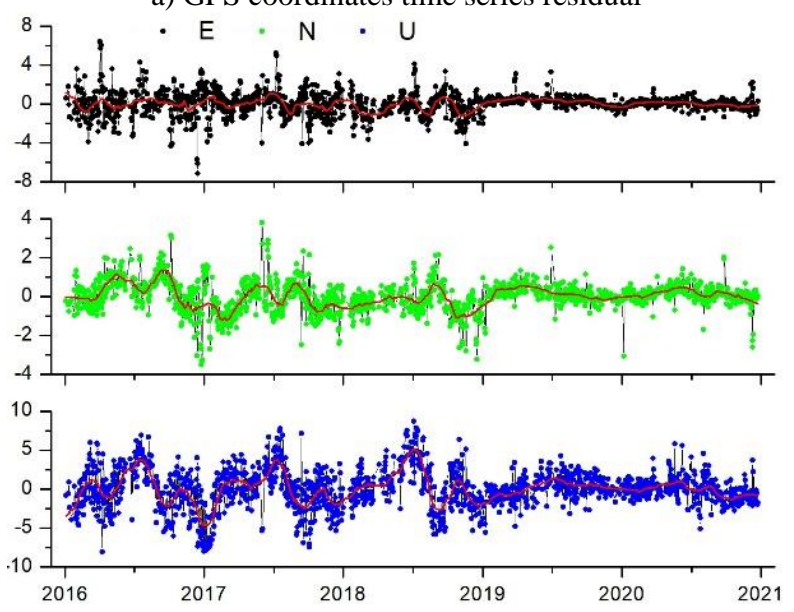

b) Beidou coordinates time series residual

Figure 4. Comparison of time series residual of coordinates after elimination of linear velocity $(\mathrm{cm})$

Table 4 show time series RMS of coordinates of stations AHBZ after elimination of linear velocity, which indicates that the RMS values in the three directions of time series of coordinates calculated from BDS data from 2019 until 2020 are approximately twice of that from GPS data. For a 5-year time span, the repeatability accuracy of time series of coordinates calculated from BDS data of the first three years is poor (about triple of that calculated from GPS data in directions $\mathrm{N}$ and $\mathrm{U}$ and quadruple in direction E), which is comparable to the RMS of all national GNSS reference stations.

\begin{tabular}{|c|c|c|c|}
\hline \multirow{2}{*}{ Station } & \multicolumn{3}{|c|}{ RMS(cm) } \\
\cline { 2 - 4 } & $\mathrm{E}$ & $\mathrm{N}$ & $\mathrm{U}$ \\
\hline GPS & 0.24 & 0.28 & 0.82 \\
BDS(2016-2020) & 1.17 & 0.78 & 2.49 \\
BDS(2016-2018) & 1.43 & 0.92 & 2.96 \\
BDS(2019-2020) & 0.50 & 0.45 & 1.46 \\
\hline
\end{tabular}

Table 4. RMS of time series residual of coordinates of stations AHBZ after elimination of linear velocity

\subsection{Station Coordinates Difference}

The RMS values in directions $\mathrm{E}, \mathrm{N}$ and $\mathrm{U}$ of time series residual of coordinates calculated from BDS data and from GPS data by subtracting coordinates calculated from GPS data from that calculated from BDS data are $1.49 \mathrm{~cm}, 0.95 \mathrm{~cm}$ and $2.66 \mathrm{~cm}$ respectively. Calculations are conducted for two periods before and after Jan. 1, 2019. The RMS values in directions ENU are 
$1.73 \mathrm{~cm}, 1.06 \mathrm{~cm}$ and $3.06 \mathrm{~cm}$ in the first period, and $0.81 \mathrm{~cm}$, $0.69 \mathrm{~cm}$ and $1.91 \mathrm{~cm}$ in the second period.
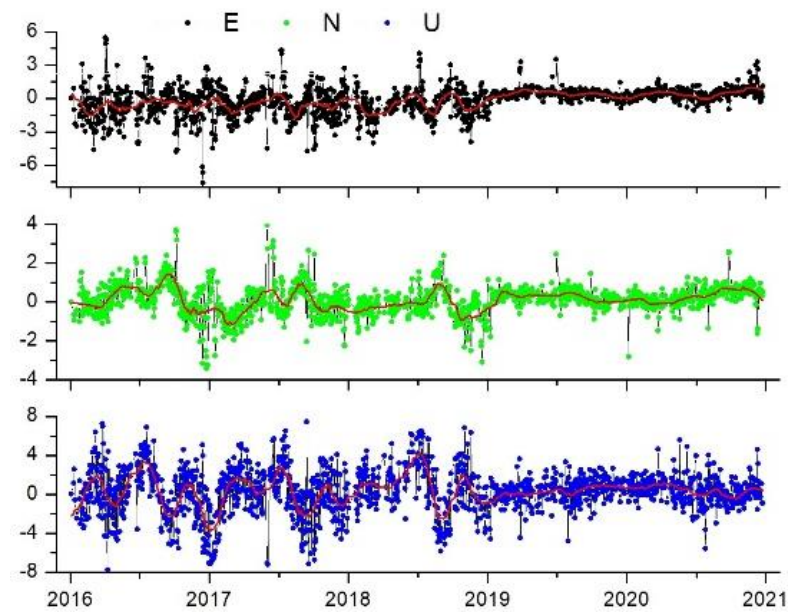

Figure 5. Station coordinates difference calculated from GPS data and from Beidou data

Figure 5 is developed based on stations AHBZ to show time series of coordinate difference calculated from GPS data and from BDS data. The RMS values of residual of AHBZ coordinates in directions ENU are $1.25 \mathrm{~cm}, 0.78 \mathrm{~cm}$ and $2.25 \mathrm{~cm}$ respectively. Figures 4 and 5 indicate that the coordinate residual before 2019 is larger than that after 2019. Statistics of coordinates residual for the two periods before and after 2019 shows that the RMS values in the three directions are $1.43 \mathrm{~cm}$, $0.90 \mathrm{~cm}$ and $2.69 \mathrm{~cm}$ respectively in the first period, and $0.54 \mathrm{~cm}$, $0.46 \mathrm{~cm}$ and $1.29 \mathrm{~cm}$ respectively in the second period, the difference in the second period is obviously smaller than that in the first period, and the repeatability in the second period is better as shown in the time series chart of coordinates calculated from BDS data.

\section{CONCLUSION}

Based on GPS data and BDS data of the national GNSS reference stations uniformly distributed across China, precise point positioning is calculated, and the difference in station coordinates calculated from GPS data and BDS data is analyzed which provides a reference for data processing for construction and maintenance of Beidou coordinate frame. Calculations show that the repeatability of station coordinate residual calculated from GPS data is superior to that calculated from BDS data on the whole. The repeatability values of reference station residual in directions ENU solely based on BDS data are about $1.2 \mathrm{~cm}, 0.8 \mathrm{~cm}$ and $2.3 \mathrm{~cm}$ respectively, which were improved to $0.6 \mathrm{~cm}, 0.6 \mathrm{~cm}$ and $1.5 \mathrm{~cm}$ respectively during 2019 2020 period since the adoption of code precision satellite orbit products. With good satellite orbit accuracy and good reference station data quality, the difference RMS values between coordinates calculated from GPS data and that from BDS data can reach $0.5 \mathrm{~cm}, 0.5 \mathrm{~cm}$ and $1.3 \mathrm{~cm}$. On the whole, the BSD data based on national GNSS reference stations can meet the needs of constructing and maintaining a centimeter-level Beidou coordinate frame.

\section{ACKNOWLEDGEMENTS}

The author would like to acknowledge the efforts of the IGS in providing the GNSS precise orbit products. This work is supported by the National Natural Science Foundation of China (No. 41804038) and the National Key Research and Development Program of China (Grant No. 2016YFB0501802).

\section{REFERENCES}

Liu J, Liu H, Zou R, Wei N. 2009. Some thoughts on the establishment of nationwide continuously operating reference stations $(J)$, Geomatics and Information Science of Wuhan University.11:1261- 265+1284(ch).

Altamimi Z., Collilieux X., M’etivier L. 2011. ITRF2008: an improved solution of the International Terrestrial Reference Frame(J), Journal of Geodesy. 85:457-473.

Altamimi Z., Rebischung P., Metivier L., Collilieux X. 2016.ITRF2014:A new release of the International Terrestrial Reference Frame modeling non-linear station motions(J).Journal of Geophysical Research: Solid Earth. 60196041.

Chen Junyong. 2008. Chinese Modern Geodetic DatumChinese Geodetic Coordinate System 2000(CGCS 2000) and Its Frame(J), Acta Geodaetica et Cartographica Sinica. 37(3), P269-271(ch).

Liu J, Liu H, Zou R, Wei N. 2009. Some thoughts on the establishment of nationwide continuously operating reference stations(J), Geomatics and Information Science of Wuhan University. 11:1261-1265,1284(ch).

Wei Ziqing. 2013. On the Coordinate System of BeiDou Navigation Satellite System. Geomatics Science and Engineering. 33(02):1-5(Ch).

Zou Rong, Liu Hui, Wei Na et al. 2011. Establishment and Maintenance of the Compass Terrestrial Reference Frame. Geomatics and Information Science of Wuhan University. 04, P431-436.

Zeng An-min, Ming Feng, Jing Yi-fan. 2015.Inspiration of Establishing DBS Terrestrial Reference Frame From Implement of WGS84. Journal of Navigation and Positioning.3(3):43$48+68$.

Shi Chuang, Wei Na, Li Min et al. 2020. Approaches to Realize and Maintain National Terrestrial Reference Frame Based on BDS Data(J). Bulletin of Surveying and Mapping. (1):111-114.

Shi Chuang, Zhao Qile, Li Min.et al. 2012. Precise orbit determination of Beidou satellites with precise positioning $(J)$. SCIENCE CHINA:Earth Sciences. 55(7) :1079-1086.

Gao Xingwei, Guo Jingjun, Cheng Pengfei,et al. 2012. Fusion positioning of Compass/GPS Based on Spatio Temporal System Unification. Acta Geodaetica et Cartographica Sinica.41(5):743-748,755.

Yang Yuanxi, Li Jinlong, Wang Aibing.et al.2014. Preliminary assessment of the navigation and positioning performance of BeiDou regional navigation satellite system $(J)$. Science China:Earth Sciences.57(1);1440152.

Wang Yuebing, You Xinzhao, Jin Honglin, et al. 2014.Accuracy Comparison of Precise Point Positioning of Beidou Navigation System with GPS(J).Journal of Geodesy and Geodynamics. 34(4):110-116.

Liu Quanhai, Wang Yankai, Chen Hua. 2020. Performance 
Analysis of high-precision Regional Reference Frame Establishment using BDS Data Only. Bulletin of Surveying and Mapping. (1):111-114.

Rebischung, P., Griffiths, J., Ray, J., Schmid, R.,Collilieux, X., \& Garayt, B. .2012. IGS08: the IGS realization of ITRF2008 (J), GPS solutions. 16(4), P483-494.

$\mathrm{Na}$ Wei.2010.Terrestrial Reference Frame and Surface Mass Redistribution Derived from GPS Data. Wuhan unveisity(ch).

Ge, M. , Gendt, G. , Dick, G. , \& Zhang, F. P. . 2005. Improving carrier-phase ambiguity resolution in global gps network solutions. Journal of Geodesy, 79(1), 103-110.

Lyard, F. , Lefevre, T. , Letellier, F. , \& Francis, O.. 2004. Modelling the globalocean tides: modern insights from fes2004. Journal of Geophysical Research Atmospheres. 56(5), 394-415.

Petit, G. , \& Luzum, B. . 2010. IERS Conventions (2010). iers technical note. 